INVITED REVIEW

\title{
Novel insights into the neuroendocrinology of critical illness
}

\author{
Greet Van den Berghe \\ Department of Intensive Care Medicine, University Hospital Gasthuisberg, Catholic University of Leuven, B-3000 Leuven, Belgium \\ (Correspondence should be addressed to G Van den Berghe; Email: greta.vandenberghe@uz.kuleuven.ac.be)
}

\begin{abstract}
An unexplained hallmark of prolonged critical illness is the fact that food does not prevent or reverse protein wasting, while fat is paradoxically accrued. This 'wasting syndrome' often persists after the underlying disease has been resolved and thus perpetuates intensive care dependency. Although the crucial role of an intact hypothalamus-pituitary axis for homeostasis during stress is well recognized, the differences between the neuroendocrine changes observed in acute and prolonged critical illness were only recently described. Novel insights in this area are reviewed here.

The initial endocrine stress response consists primarily of a peripheral inactivation of anabolic pathways while pituitary activity is essentially amplified or maintained. These responses presumably provide the metabolic substrates and host defense required for survival and to delay anabolism, and thus should be considered as adaptive and beneficial. Persistence of this acute stress response throughout the course of critical illness was hitherto assumed. This assumption has now been invalidated, since a uniformly reduced pulsatile secretion of ACTH, TSH, LH, prolactin (PRL) and GH has been observed in protracted critical illness, causing diminished stimulation of several target organs. Impaired pulsatile secretion of anterior pituitary hormones in the chronic phase of critical illness seems to have a hypothalamic rather than a pituitary origin, as administration of relevant releasing factors evoked immediate and pronounced pituitary hormone release. A reduced availability of TRH, one of the endogenous ligands of the GH-releasing peptide (GHRP) receptor (such as the recently discovered ghrelin) and, in very long-stay critically ill men, also of GHRH, appear to be involved. This hypothesis was further explored by investigating the effects of continuous i.v. infusion of GHRH, GHRP, TRH and their combinations for several days. Pulsatile secretion of GH, TSH and PRL was re-amplified by relevant combinations of releasing factors which also substantially increased circulating levels of IGF-I, GH-dependent binding proteins, thyroxine and tri-iodothyronine (T3) while avoiding a rise in reverse T3. Active feedback-inhibition loops prevented overstimulation of target organs and metabolic improvement was noted with the combined infusion of GHRP and TRH. Whether this novel endocrine strategy will also enhance clinical recovery from critical illness remains to be explored.
\end{abstract}

European Journal of Endocrinology 143 1-13

\section{Introduction}

By definition, critical illness is any condition requiring support for failing vital organ functions, either with mechanical aids (such as mechanical ventilation, hemodialysis or -filtration or cardiac-assist devices) or with pharmacological agents (such as inotropes or vasopressors), without which death would ensue. Undoubtedly, this condition is the ultimate example of acute, severe physical stress. If onset of recovery does not follow within several days of intensive medical care, critical illness often becomes prolonged and intensive care must be continued for weeks or even months. At this stage, and in contrast to the early phase of severe illnesses, patients no longer efficiently use fatty acids as metabolic substrates (1). They store fat with feeding, both in adipose tissue and as fatty infiltrates in vital organs such as the pancreas and the liver, but they continue to lose large amounts of protein from skeletal muscle and from organs, which causes impairment of vital functions, weakness and delayed or hampered recovery (2). This is a major and frustrating clinical problem as it leads to persistent dependency on intensive medical care - despite adequate and successful treatment of the underlying disease that had initially warranted admission to the intensive care unit - with increasing susceptibility to potentially lethal complications, mostly of infectious origin. Indeed, mortality from prolonged critical illness is high: $24 \%$ for a group of adult patients with an intensive care stay of $>21$ days in our intensive care unit (3). Incidentally, male patients seem to have a higher risk for an adverse outcome of prolonged critical illness $(26 \%)$ than female patients $(20 \%)$ (3). The reason for this gender difference in 
outcome remains obscure. In line with the foregoing is the inability of the classical scoring systems for severity of illness, such as the Acute Physiology And Chronic Health score (APACHE II) (4), to predict mortality in this type of long-stay, intensive care patient. This enigma reflects the current absence of knowledge on the pathophysiological mechanisms underlying onset of recovery or, conversely, the lack of recovery in prolonged critically ill patients.

The importance of an intact hypothalamus-pituitary axis for metabolic and immunological homeostasis during stress is well recognized. However, most of the data on the neuroendocrine stress response have been obtained in human and animal models of acute stress such as surgery, trauma and acute infection. The neuroendocrine changes in prolonged critical illness were assumed (mainly by extrapolation) to be identical to those observed in the above-mentioned models of acute stress. This assumption has now been invalidated (5). Indeed, it recently became clear that hypothalamus-anterior pituitary function is altered differently in the acute phase (the first hours to days) and the chronic phase (from 7 to 10 days onwards) of critical illness (5) and a recent study has revealed that a neuroendocrine 'dysfunction' at least partially underlies several metabolic problems present in the chronic phase of illness (6). This review, which for the sake of brevity has omitted a number of papers from the discussion, attempts to give an integrated update of the knowledge on the neuroendocrine responses to acute and prolonged critical illness in the human, focusing on the somatotropic and thyroid axes.

\section{Changes within the somatotropic axis}

In normal physiology, growth hormone $(\mathrm{GH})$ is released from the somatotropes in a pulsatile fashion, under the interactive control of the stimulatory hypothalamic GHreleasing hormone (GHRH) and the inhibitory somatostatin (7). Since the 1980s, a series of synthetic GHreleasing peptides (GHRPs) and non-peptide analogs have been developed that potently release $\mathrm{GH}$, through a specific G-protein coupled receptor located in the hypothalamus and the pituitary $(8,9)$. It now appears that there exists at least one highly conserved endogenous ligand for this receptor (10), named 'ghrelin', which originates in peripheral tissues such as the stomach, as well as in the hypothalamic arcuate nucleus, and which seems to be another key factor in the complex physiological regulation of pulsatile $\mathrm{GH}$ secretion. As clearly shown in rodents (11), there is now evidence that in humans, too (12), the pulsatile nature of $\mathrm{GH}$ secretion is important for its metabolic effects $(3,13)$.

\section{Changes in the acute phase of critical illness}

During the first hours or days after an acute, stressful insult, such as surgical or traumatic injury or infection, circulating GH levels become elevated and the normal GH profile, consisting of peaks alternating with virtually undetectable troughs, is altered: peak GH levels as well as interpulse concentrations are high and the $\mathrm{GH}$ pulse frequency is elevated $(5,14,15)$ (Fig. 1). It is still unclear as to which factor ultimately controls the stimulation of GH release in response to stress. First, as in starvation (16), more frequent withdrawal of the inhibitory somatostatin and/or an increased availability of stimulatory (hypothalamic and/or peripheral) $\mathrm{GH}$ releasing factors could, hypothetically, be involved. Secondly, serum concentrations of insulin-like growth factor-I (IGF-I) and the GH-dependent binding protein IGFBP-3 and its acid-labile subunit (ALS) decrease; this is preceded by a drop in the serum levels of GH-binding protein (GHBP) (17). The latter was found to reflect reduced GH-receptor expression in peripheral tissues (17). Circulating levels of the small (inhibitory) IGFbinding proteins, such as IGFBP-1, IGFBP-2 and IGFBP-6 are elevated $(18,19)$. This constellation of effects, which has been confirmed in experimental human and animal models of acute stress and in acutely ill patients, has been interpreted as acquired peripheral resistance to $\mathrm{GH}(14,18)$. This is probably brought about by the effects of cytokines such as tumor necrosis factor- $\alpha$ (TNF- $\alpha$ ), interleukin-1 (IL-1) and interleukin-6 (IL-6). It has been hypothesized though it remains unproved - that reduced GH-receptor expression and thus low circulating IGF-I levels are the

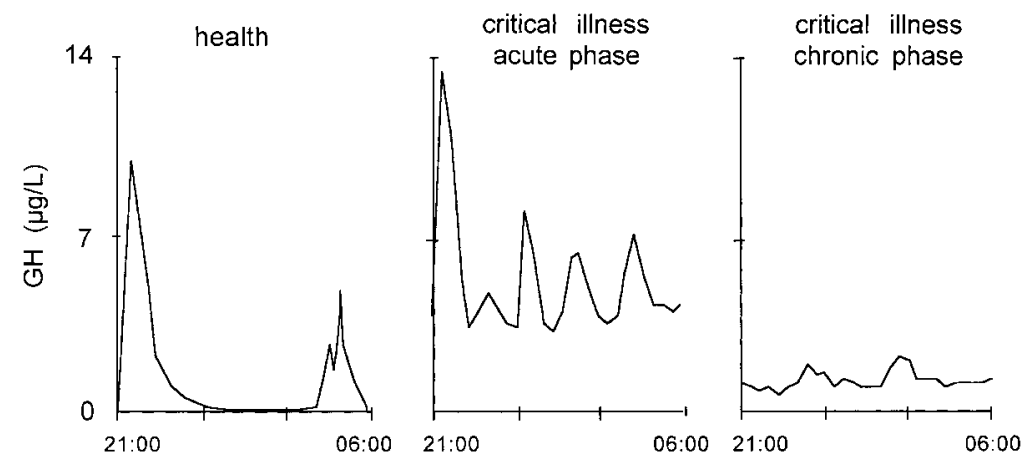

www.eje.org
Figure 1 Nocturnal serum concentration profiles of $\mathrm{GH}$ illustrating the differences between the acute phase and the chronic phase of critical illness within an intensive care setting. Adapted, with permission, from (5). 
primary events (cytokine-induced) which in turn through reduced negative feedback inhibition - drives the abundant release of GH during acute stress, exerting direct lipolytic, insulin-antagonizing and immune-stimulatory actions, while the indirect IGF-I-mediated somatotropic effects are attenuated $(20,21)$. This phenomenon would make a lot of sense in stressful conditions. Indeed, the set of alterations within the GHIGF-I axis could contribute to the provision of metabolic substrates (glucose, free fatty acids, amino acids such as glutamine) for vital organs such as the brain and the heart and for host defense and thus can be conceived as adaptive and beneficial for survival. However, an increased IGFBP-3 protease activity in plasma has also been reported $(18,22)$ and is thought to result in increased dissociation of IGF-I from the ternary complex and, hence, a shortening of IGF-I half-life in the circulation. The latter could theoretically be an adaptive escape mechanism to secure the availability of free IGF-I at tissue level (22).

\section{Changes in the chronic phase of critical illness}

In prolonged critical illness, the changes observed within the somatotropic axis are different. First, the pattern of $\mathrm{GH}$ secretion is very chaotic and the amount of $\mathrm{GH}$ which is released in pulses is now much reduced compared with the acute phase $(6,23,24)$ (Fig. 1). Moreover, although the non-pulsatile fraction is still somewhat elevated and the number of pulses is still high, mean nocturnal GH serum concentrations are hardly elevated when compared with the healthy, nonstressed condition, and are substantially lower than in the acute phase of stress (5). We observed that, when intensive care patients are studied from 7-10 days of illness onwards in the absence of drugs known to exert profound effects on $\mathrm{GH}$ secretion (such as dopamine $(25,26)$, calcium-entry blockers or glucocorticoids, to name but a few) they present very uniformly with mean nocturnal GH levels of about $1 \mu \mathrm{g} / \mathrm{l}$, trough levels that are easily detectable and thus still elevated and peak $\mathrm{GH}$ levels that hardly ever exceed $2 \mu \mathrm{g} / \mathrm{l}$; these results are, surprisingly, independent of the patient's age, gender, body composition and type of underlying disease $(3,5)$. Secondly, the pulsatile component specifically of GH secretion - which is substantially reduced - has been found to correlate positively with circulating levels of IGF-I, IGFBP-3 and the ALS - all of which are low (6, $23,24)$. In other words, the more pulsatile GH secretion is suppressed, the lower circulating levels of the GHdependent IGF-I and ternary complex binding proteins become. This is not what one would expect if GH resistance were the primary cause of the low IGF-I levels, as that would result in an inverse correlation or no correlation between GH secretion and IGF-I levels. The recently documented elevated serum levels of GHBP (3), assumed to reflect GH-receptor expression in peripheral tissues, in prolonged critically ill patients compared with those measured in a matched control group are in line with recovery of GH-responsiveness with time during severe illness $(3,6)$. It seems that the lack of pulsatile $\mathrm{GH}$ secretion in conditions of prolonged stress contributes to the low circulating levels of IGF-I and ternary complex binding proteins. Moreover, it was demonstrated that these low serum levels of $\mathrm{GH}-$ dependent IGF-I and binding proteins (IGFBP-3, ALS, IGFBP-5) are tightly related to biochemical markers of impaired anabolism, such as low serum osteocalcin and leptin concentrations during prolonged critical illness (6). Together, these findings suggest that a relative hyposomatotropism, a lack of pulsatile $\mathrm{GH}$ secretion, participates in the pathogenesis of the 'wasting syndrome' especially in the chronic phase of critical illness. In line with a higher risk of an adverse outcome associated with male gender (3), men appear to do worse than women in the sense that they lose more of the pulsatility and regularity within the GH-secretory pattern when critical illness progresses (despite an indistinguishable total GH output) and concomitantly reveal even lower IGF-I and ALS levels than their female counterparts (3) (Fig. 2). It remains unclear if this sexual dimorphism within the GH-IGF-I axis is causally related to the gender difference in outcomes of prolonged critical illness or if it merely reflects a casual association.

\section{Pathophysiology of chronic changes}

The next question is why pulsatile GH secretion is reduced in prolonged critical illness. Is the pituitary
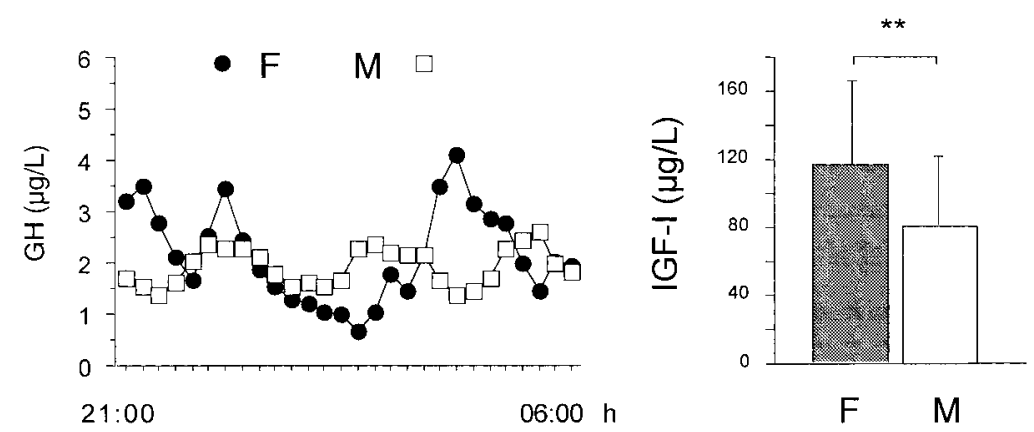

Figure 2 The more 'feminized' pattern of $\mathrm{GH}$ secretion (more irregular and less pulsatile $\mathrm{GH}$ secretory pattern for an identical mean nocturnal GH level) in men with prolonged critical illness compared with women is illustrated by the representative nocturnal $(2100 \mathrm{~h}-0600 \mathrm{~h}) \mathrm{GH}$ serum concentration series (sampling every $20 \mathrm{~min}$ ) obtained in a male $(\square)$ and a matched female $(\bullet)$ patient. Concomitantly, men with protracted critical illness have lower circulating levels of IGF-I than female patients. IGF-I results are presented as means \pm S.D. ${ }^{\star \star} P<0.01$. Adapted, with permission, from (3). 


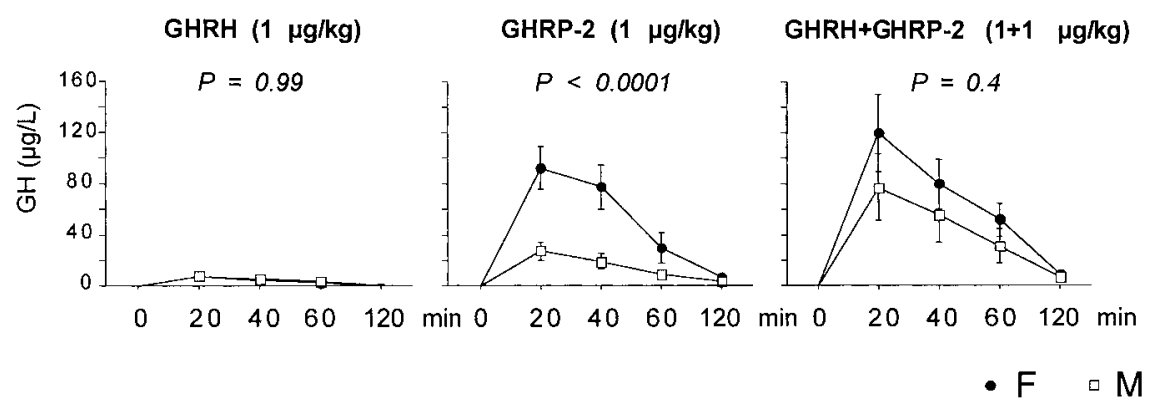

Figure 3 Responses (increments above baseline) of GH obtained 20, 40, 60 and 120 min after i.v. bolus administration of $\mathrm{GHRH}(1 \mu \mathrm{g} / \mathrm{kg})$, GHRP-2 $(1 \mu \mathrm{g} / \mathrm{kg})$, and GHRH+GHRP-2 $(1+1 \mu \mathrm{g} / \mathrm{kg})$ in matched male and female patients with protracted critical illness. Five men and five women were randomly allocated to each secretagogue group. Results are presented as means \pm S.E.M.: $\bullet$, females; $\square$ males. $P$ values were obtained using repeated ANOVA measurements. Adapted, with permission, from (3).

participating in the 'multiple organ failure syndrome', becoming unable to synthesize and secrete GH? Or, alternatively, is the lack of pulsatile GH secretion due to increased somatostatin tone and/or reduced stimulation by the endogenous releasing factors such as GHRH and/or ghrelin? Studying GH responses to the administration of GH-secretagogues (GHRH and GHRP), in a dose which is known to evoke a maximal GH response in healthy volunteers, enables - to a certain extent differentiation between a primarily pituitary origin and a hypothalamic origin of the relatively impaired $\mathrm{GH}$ release in critically ill patients. Indeed, the combined administration of GHRH and GHRP appears to be the most powerful stimulus for pituitary GH release in humans (27). Thus a low GH response in critical illness would fit with a pituitary dysfunction and/or high somatostatin tone and a high GH response would be compatible with reduced (hypothalamic) stimulation of the somatotropes.

We found that $\mathrm{GH}$ responses to a bolus injection of GHRP are high in long-stay, intensive care patients and several-fold higher than the response to GHRH, the latter being normal or often subnormal (28). GHRH+GHRP evokes a clear synergistic response in this condition, revealing the highest $\mathrm{GH}$ responses ever reported in a human study (28). The high GH responses to secretagogues exclude the possibility that the blunted $\mathrm{GH}$ secretion during protracted critical illness is due either to a lack of pituitary capacity to synthesize $\mathrm{GH}$ or to accentuated somatostatin-induced suppression of GH release. Inferentially, one of the mechanisms which could be involved is reduced availability of ghrelin or another putative endogenous ligand for the GHRP receptor. Ultimately, the combination of low availability of somatostatin and of an endogenous GHRP-like ligand emerges as a plausible mechanism that clarifies (i) the reduced GH burst amplitude, (ii) the increased frequency of spontaneous GH secretory bursts and (iii) the elevated interpulse levels as well as (i.v.) the striking responsiveness to GHRP alone or in combination with GHRH, and this without markedly increased responsiveness to GHRH alone. Female patients with prolonged critical illness have a markedly higher response to a bolus of GHRP compared with male patients, a difference which is eliminated when GHRH is injected together with GHRP (3) (Fig. 3). Lower endogenous GHRH action in men with prolonged critical illness, possibly due to the concomitant profound hypoandrogenism (3), accompanying loss of action of an endogenous GHRP-like ligand with prolonged stress in both genders, may explain this finding.

\section{Effects of releasing factors in the chronic phase of critical illness}

The hypothesis of reduced endogenous stimulation of GH secretion in prolonged critical illness was further explored by examining the effects of continuous infusion of GHRP \pm GHRH. Continuously infusing GHRP $(1 \mu \mathrm{g} / \mathrm{kg} / \mathrm{h})$, and, to a greater extent, GHRH+GHRP $(1+1 \mu \mathrm{g} / \mathrm{kg} / \mathrm{h})$, for up to 2 days was found to substantially amplify pulsatile $\mathrm{GH}$ secretion (>6-fold and $>10$-fold respectively) in this condition, without altering the relatively high burst frequency (23, 24) (Fig. 4). Reactivated pulsatile GH secretion was accompanied by a proportionate rise in serum IGF-I (66 and 106\%), IGFBP-3 (50 and 56\%) and ALS (65 and $97 \%)$, indicating peripheral GH-responsiveness $(23,24)$ (Fig. 4). The presence of considerable responsiveness to reactivated pulsatile $\mathrm{GH}$ secretion in these patients and the high serum levels of GHBP clearly delineate the distinct pathophysiological paradigm present in the chronic phase of critical illness as opposed to the acute phase, which is thought to be primarily a condition of GH-resistance. After 2 days of treatment with GHRP, (near-) normal levels of IGF-I, IGFBP-3, IGFBP-5 and ALS are reached and, as shown in a subsequent study, maintained for at least 5 days (6) (Fig. 5). GH secretion after 5 days of treatment with GH-secretagogues was found to be lower than that after 2 days, suggesting active feedback-inhibition loops which probably prevented overtreatment $(6,24)$. In this study, in which GHRP was infused together with TRH for 5 days, the self-limited endocrine responses induced a shift towards 

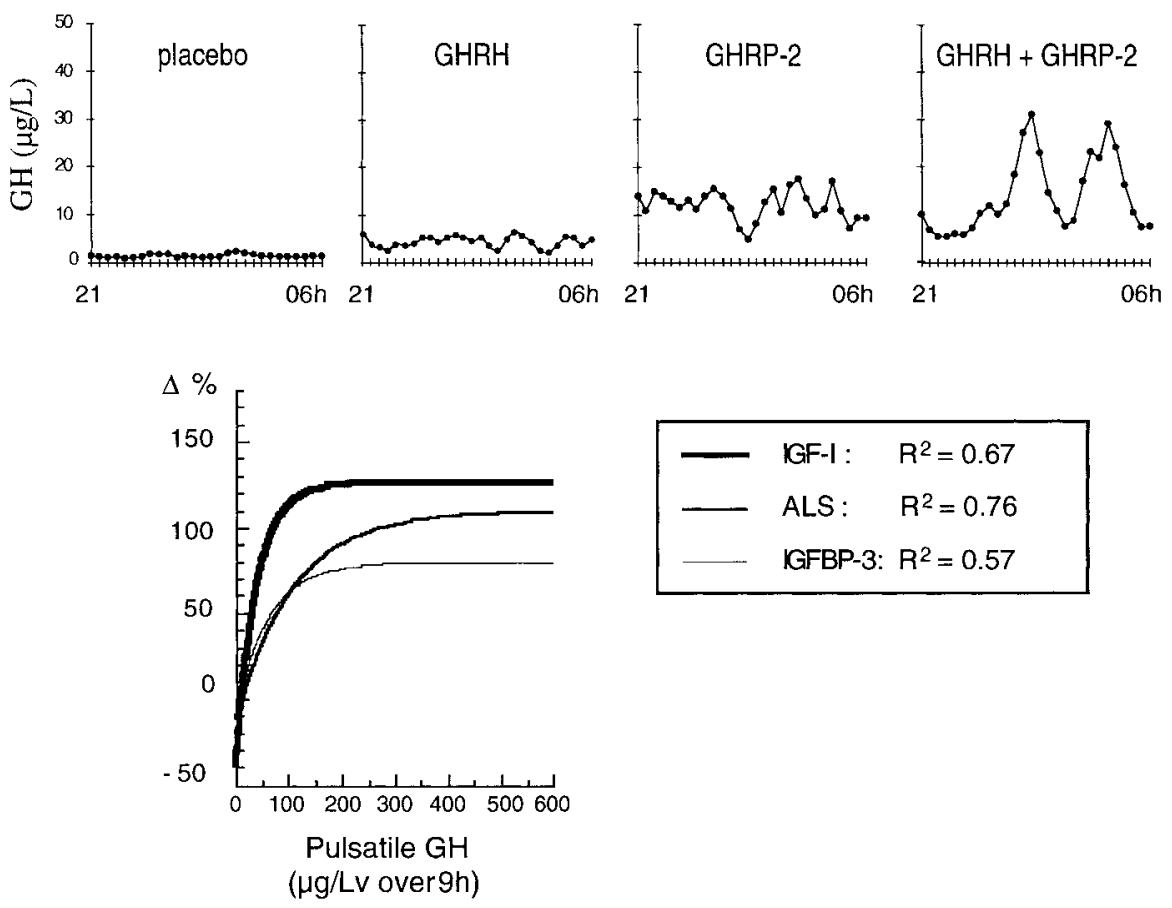

Figure 4 Nocturnal serum GH profiles in the prolonged phase of illness, illustrating the effects of continuous infusion of placebo, GHRH (1 $\mu \mathrm{g} / \mathrm{kg} / \mathrm{h})$, GHRP-2 $(1 \mu \mathrm{g} / \mathrm{kg} / \mathrm{h})$ or GHRH+GHRP-2 $(1+1 \mu \mathrm{g} / \mathrm{kg} / \mathrm{h})$. Exponential regression lines have been reported between pulsatile GH secretion and the changes in circulating IGF-I, ALS and IGFBP-3 obtained with $45 \mathrm{~h}$ infusion of placebo, GHRP-2 or GHRH+GHRP-2. They indicate that the parameters of $\mathrm{GH}$-responsiveness increase in proportion to $\mathrm{GH}$ secretion, up to a certain point, beyond which further increases in $\mathrm{GH}$ secretion apparently have little or no additional effect. It is noteworthy that the latter point corresponds to a pulsatile $\mathrm{GH}$ secretion of approximately $200 \mu \mathrm{g} / \mathrm{Lv}$ over $9 \mathrm{~h}$, or less, a value that can usually be evoked by the infusion of GHRP-2 alone. In the chronic, non-thriving phase of critical illness, GH-sensitivity is clearly present, in contrast to the acute phase of illness, which is thought to be primarily a condition of $\mathrm{GH}$ resistance. From (5), with permission.

anabolism at the level of several peripheral tissues, as indicated by a rise in serum levels of osteocalcin, insulin and leptin and a decrease in urea production (6). Usually, infusion of GHRP without GHRH suffices to

reactivate pulsatile GH secretion and to elicit the IGF-I and IGFBP responses in prolonged critical illness. However, in critically ill men, in particular those with a very long intensive care stay, it may be necessary to
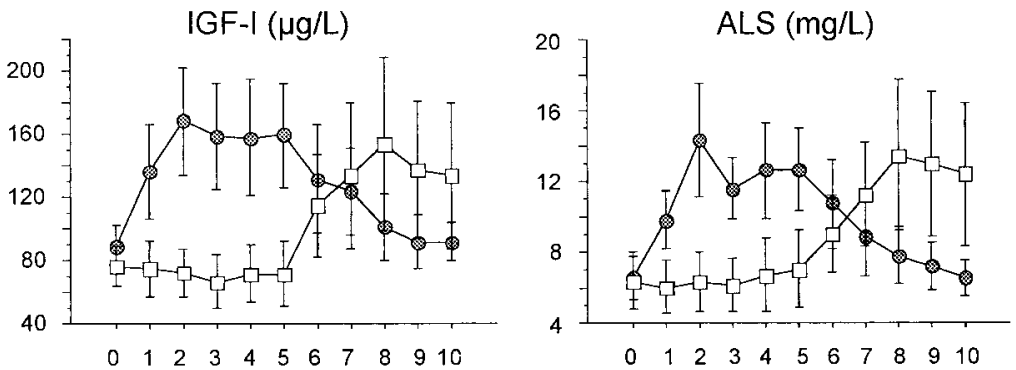

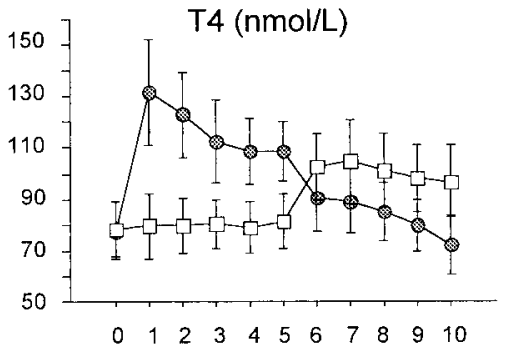

day of treatment

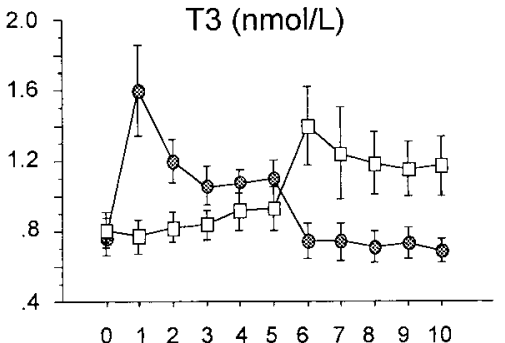

day of treatment
Figure 5 Serum concentrations (means \pm S.E.M.) of IGF-I, ALS, T4 and T3 in response to a randomized treatment with either 5 days of GHRP-2+TRH infusion $(1+1 \mu \mathrm{g} / \mathrm{kg} / \mathrm{h})$ followed by 5 days of placebo (-) or 5 days of placebo followed by 5 days of GHRP-2+TRH infusion (1+1 $\mu \mathrm{g} / \mathrm{kg} / \mathrm{h})(\square)$ in a group of 10 male and 4 female patients with prolonged critical illness. All $P<0.0001$ (ANOVA).

The mean age of the patients was 68 years. The mean intensive care stay at the start of the study was 40 days. Adapted with permission from (6). 


\section{Acute}

changes in peripheral metabolism and binding

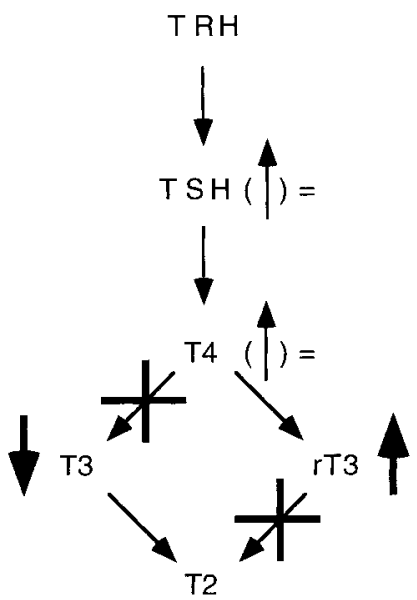

add a low dose of GHRH $(0.1 \mu \mathrm{g} / \mathrm{kg} / \mathrm{h}$ seems to be sufficient) (G. Van den Berghe, unpublished observations) because of the simultaneous lack of endogenous GHRH activity accompanying the reduced availability of the GHRP-like ligand (3).

\section{Changes within the thyroid axis}

The changes within the thyroid axis have a similar dual presentation (Fig. 6).

\section{Changes in the acute phase of critical illness}

Within $2 \mathrm{~h}$ after the onset of severe physical stress, such as surgery or trauma, serum levels of tri-iodothyronine (T3) decrease, whereas thyroxine (T4) and thyrotropin (TSH) briefly rise (29). Apparently, low T3 levels at that stage are mainly caused by a decreased peripheral conversion of T4 to T3 (30). Subsequently, circulating TSH and T4 levels often return to 'normal' whereas T3 levels remain low. Although mean serum TSH concentrations are indistinguishable from normal values at that time point, the normal nocturnal TSH surge has been shown to be absent $(31,32)$. The magnitude of the T3 drop within $24 \mathrm{~h}$ has been found to reflect the severity of the illness $(33,34)$. The cytokines TNF- $\alpha$, IL-1 and IL- 6 have been investigated as putative mediators of the acute low-T3 syndrome. Although these cytokines are capable of mimicking the acute stress-induced alterations in thyroid status, cytokine antagonism in sick mice failed to restore normal thyroid function (35). Low concentrations of binding proteins and inhibition of hormone binding, transport and metabolism by elevated levels of free fatty acids and bilirubin have been proposed as factors contributing to the low-T3 syndrome at tissue level (36). The acute changes in the thyroid axis have been interpreted teleologically as an attempt to reduce energy expenditure, at least when they occur during starvation (37), and thus as an appropriate response that does not warrant intervention. Whether this is also applicable to other acute stress conditions, such as surgery, infection or the initial phase of critical illness, is still a matter of controversy (38). Indeed, although short-term i.v. administration of T3 to patients after cross-clamp removal during elective coronary bypass grafting has been shown to improve postoperative cardiac function $(39,40)$, the pharmacological doses of T3 which resulted in supranormal serum T3 levels and the absence of an effect on outcome do not allow refutation of the postulated adaptive nature of the 'acute' low-T3 syndrome.

\section{Changes in the chronic phase of critical illness}

Patients treated in intensive care units for weeks or months, however, present with a different set of changes within the thyroid axis. A single sample usually reveals low or low/normal TSH values for a given assay and low T4 and T3 serum concentrations (41). However, overnight repeated sampling revealed that, essentially, the pulsatility in the TSH secretory pattern is dramatically diminished and that, as for the $\mathrm{GH}$ axis, it is the loss of TSH pulse amplitude which is related to low serum levels of thyroid hormone (41). Moreover, Fliers and coworkers have elegantly demonstrated (by postmortem examination of human brain specimens) that when death follows chronic severe illness, the expression of the TRH gene in hypothalamic paraventricular 
nuclei is reduced whereas this is not the case after death from acute insults such as lethal trauma due to a road accident (42). These researchers observed a positive correlation between TRH mRNA in the paraventricular nuclei and blood levels of TSH and T3. Together, these findings indicate that production and/or release of thyroid hormones is reduced in the chronic phase of critical illness, due to impaired hypothalamic stimulation of the thyrotropes, in turn leading to reduced functioning of the thyroid gland. In line with this concept is the rise in TSH marking the onset of recovery from severe illness (43). The exact mechanisms underlying the neuroendocrine pathogenesis of the low thyroid hormone levels in prolonged critical illness is unknown. As circulating cytokine levels are usually low at that stage (44), other mechanisms operational within the central nervous system are presumably involved. Endogenous dopamine and prolonged hypercortisolism may each play a role since exogenous dopamine as well as glucocorticoids are known to provoke or severely aggravate hypothyroidism in critical illness $(45,46)$. A recent study has shown, for the first time, that low thyroid hormone levels in protracted critical illness, found to correlate inversely with urea production and bone degradation, do not reflect an adaptive, protective mechanism against hypercatabolism (6). Indeed, the restoration of physiological levels of thyroid hormones by continuously infusing TRH (together with a GHsecretagogue) (Fig. 5) was found to reduce hypercatabolism (6), an effect which was related only to the changes in thyroid hormone levels. During TRH infusion in prolonged critical illness, the negative feedback exerted by thyroid hormones upon the thyrotropes was found to be maintained, thus precluding overstimulation of the thyroid axis (24). This selflimitation may be extremely important during critical illness in order to avoid hyperthyroidism, which would inadvertently aggravate catabolism. The co-infusion of $\mathrm{TRH}$ and $\mathrm{GH}-$ releasing factors appears to be a better strategy than the infusion of TRH alone, since the combination, but not TRH alone, increases the pulsatile fraction of TSH release and avoids a rise in circulating reverse T3 (24). The latter points to the well-known effect of $\mathrm{GH}$ on the activity of type I deiodinase and eventually to other important interactions among different anterior pituitary axes for optimal peripheral responses (47). It remains a matter for speculation, however, as to whether correction of the low serum- and tissue concentrations of $\mathrm{T} 3$ also improves clinical problems distinctively associated with prolonged critical illness $(48,49)$, such as diminished cognitive status with lethargy, somnolence or depression; ileus and cholestasis; pleural and pericardial effusions; glucose intolerance and insulin resistance; and hyponatremia, anemia and deficient clearance of triglycerides. So far, pioneering studies with $\mathrm{T} 4$ administration have failed to demonstrate clinical benefits within an intensive care setting, but in view of the impaired conversion of $\mathrm{T} 4$ to
T3 this is not really surprising $(50,51)$. A very recent report on thyroid hormone treatment during the entire stay on the intensive care unit involving substitution doses of $\mathrm{T} 3$ in pediatric patients after correction of congenital anomaly revealed improvement in postoperative cardiac function (52). In contrast to treatment with thyroid hormones, infusing TRH allows for peripheral shifts in thyroid hormone metabolism during intercurrent events and, accordingly, permits the body to elaborate appropriate concentrations of thyroid hormones in the circulation and at tissue level, thus setting the scene for a treatment safer than the administration of T3 (24). Outcome benefit of TRH infusion alone or in combination with GHsecretagogues in prolonged critical illness has yet to be studied.

\section{Parallel changes within the other anterior pituitary axes}

In line with the observations within the somatotropic and thyrotropic axes, pulsatile release of prolactin (PRL) and of luteinizing hormone - hormones which are initially released in response to stress (53-55) - also becomes impaired in the chronic phase of critical illness (56).

\section{Prolactin}

The changes in PRL may be interpreted as related to changes in immune function during the course of critical illness. The evidence for this includes the presence of PRL receptors on human T- and Blymphocytes (57) and the PRL dependency of Tlymphocytes for maintaining immune competence (58). In mice, inhibition of PRL release results in impaired lymphocyte function, in depressed lymphokine-dependent macrophage activation and in death from a normally non-lethal exposure to bacteria (59). The immune-suppressive drug cyclosporin is known to compete with PRL for a common binding site on T-cells, which may explain part of its effects $(60,61)$. The PRLsuppressing drug bromocriptine has been shown to be an adjuvant immunosuppressant in humans after heart transplantation (61). PRL was among the first hormones known to show increased serum concentrations in response to acute physical or psychological stress (62), a rise that may be mediated by vasoactive intestinal polypeptide (VIP), oxytocin, dopaminergic pathways and/or other still uncharacterized factors. Cytokines may again play a signaling role. Whether hyperprolactinemia during the initial phase of critical illness contributes to the vital initial activation of the immune cascade remains speculative.

In the chronic phase of critical illness, serum PRL levels are no longer as high as in the acute phase and the secretory pattern is characterized by a reduced pulsatile fraction $(24,37)$. A role for endogenous 
dopamine has been suggested (63). It is unknown whether the blunted PRL secretion in the chronic phase plays a role in the anergic immune dysfunction or in the increased susceptibility for infections characterizing the chronically ill (64). However, exogenous dopamine, often infused as an inotropic drug in intensive caredependent patients, has been shown to further suppress PRL secretion and was found to aggravate concomitantly both T-lymphocyte dysfunction and impaired neutrophyl chemotaxis $(63,65)$.

\section{Luteinizing hormone-testosterone axis}

For luteinizing hormone (LH), too, the pulsatility in the secretory pattern is important for its bioactivity (66, 67). Since testosterone is the most important endogenous anabolic steroid, changes within the LHtestosterone axis in the male could be relevant to the catabolic state of critical illness. A variety of catabolic states are indeed accompanied by low serum testosterone levels in men. These conditions include starvation $(68,69)$, the postoperative phase (53), myocardial infarction (54), burn injury $(70,71)$, psychological and physical stress $(72,73)$ and prolonged critical illness (56).

The low serum testosterone concentrations despite elevated LH levels documented during the acute stress of surgery or myocardial infarction (53-55) suggest an immediate stress-induced Leydig-cell suppression, the exact cause of which remains obscure. A role for inflammatory cytokines (IL-1 and IL-2) is possible, as suggested by experimental studies $(74,75)$. It may be considered appropriate that the secretion of anabolic androgens be switched off in circumstances of acute stress, in order to reduce the consumption of energy and substrates for, at that time at least, less vital functions.

When a severe stress condition, such as critical illness, becomes prolonged, hypogonadotropism ensues (70, 76). Concomitantly, circulating levels of testosterone become extremely low (often undetectable) in men whereas estradiol concentrations are increased in both genders, the latter conceivably because of increased aromatization of adrenal androgens (3). The progressive decrease in serum gonadotropin levels, however, appears to lag behind the rapid decline in serum testosterone $(54,55,77)$. In men with prolonged critical illness, a high LH pulse frequency with an abnormally low LH pulse amplitude has been observed (56); this was interpreted as an impaired compensatory LH hypersecretion in response to the very low serum testosterone levels. Thus, again it seems to be mainly an impairment of the pulsatile component of LH secretion that occurs in response to the sustained stress of prolonged critical illness (56). Endogenous dopamine, opiates and the elevated estradiol levels (3) may be involved in the pathogenesis of hypogonadotropism, as exogenous dopamine, opioids and estrogens may further diminish blunted LH secretion $(56,78)$.
Animal data suggest that prolonged exposure of the brain to IL-1 may also play a role through the suppression of LH-releasing hormone (LHRH) synthesis (74). The pioneering studies evaluating androgen treatment in prolonged critical illness failed to demonstrate conclusive clinical benefit (79). In view of the secretory characteristics of the other anterior pituitary hormones, the therapeutic potential of androgens should perhaps be reappraised in a combined treatment. Treatment with pulsatile gonadotropin-releasing hormone $(\mathrm{GnRH})$ administration is an alternative option one which is currently being explored.

\section{Pituitary-adrenal axis}

The pituitary-adrenal axis also responds differently to acute and chronic insults. It has been known for a long time that the vital stress-induced hypercortisolism induced by surgery, trauma or sepsis is associated with augmented adrenocorticotropin hormone (ACTH) release, which, in turn, is presumably driven by corticotropin-releasing hormone $(\mathrm{CRH})$, cytokines and the noradrenergic system. Concomitantly, circulating aldosterone rises markedly, probably under the control of an activated renin-angiotensin system (80). Hypercortisolism acutely shifts carbohydrate, fat and protein metabolism, so that energy is instantly and selectively available to vital organs such as the brain and so that anabolism is delayed. Intravascular fluid retention and the enhanced inotropic and vasopressor response to respectively catecholamines and angiotensin II offer hemodynamic advantages in the 'fight or flight' reflex. In addition, the hypercortisolism elicited by acute disease or trauma can be interpreted as an attempt by the organism to dampen down its own inflammatory cascade, thus protecting itself against over responses (81-83).

In prolonged critical illness, serum ACTH was found to be low while cortisol concentrations remained elevated, indicating that cortisol release may in this phase be driven through an alternative pathway, possibly involving endothelin (84). Why ACTH levels are low in prolonged critical illness is unclear; a role for atrial natriuretic peptide or substance $\mathrm{P}$ has been suggested (84). In contrast to serum cortisol levels, circulating levels of adrenal androgens such as dehydroepiandrosterone sulphate (DHEAS), which has immunostimulatory effects on Th1-helper cells, are low during prolonged critical illness (85-87). Moreover, despite increased plasma renin activity, paradoxically reduced concentrations of aldosterone are found in protracted critical illness (88). This constellation of effects suggests a shift of pregnenolone metabolism away from both mineralocorticoid and adrenal androgen pathways toward the glucocorticoid pathway, orchestrated by an unknown peripheral driving force. Ultimately, the latter mechanism may also fail, as indicated by a 20-fold higher incidence of adrenal 
insufficiency in critically ill patients over the age of 50 years and being treated on the intensive care unit for more than 14 days (89). The fact that this type of relative adrenal failure coincides with adverse outcomes suggests that high levels of glucocorticoids remain essential for hemodynamic stability. Whether hypercortisolism in the chronic phase of critical illness is exclusively beneficial remains uncertain. Sustained hypercortisolism in the presence of low levels of DHEAS and PRL could theoretically evoke an imbalance between immunosuppressive and immunostimulatory pathways and thus could be seen as participating in the increased susceptibility to complications due to infection. Other conceivable - though unproven - drawbacks of prolonged hypercortisolism include impaired wound healing and myopathy, complications that are often observed during protracted critical illness.

\section{Is the outcome of critical illness related to the neuroendocrine changes?}

In the acute phase of critical illness, parameters reflecting the severity of the insult, such as a high APACHE II score (4) and high serum cortisol and/or low T3 concentrations (33), indicate a poor prognosis. In patients with prolonged critical illness, however, these markers lack sensitivity. Recently, preliminary data were published showing that another parameter - the serum concentration of IGFBP-1 - seems to predict the outcome of prolonged critical illness (3, 6) (Fig. 7). IGFBP-1 is a small IGF-binding protein produced almost exclusively in the liver (except in pregnancy). It is distinct among the members of the IGFBP family in being acutely regulated by metabolic stimuli (90). Studies with cultured human liver explants suggest that the major regulatory influences on IGFBP-1 production are insulin, which is inhibitory, and hepatic substrate deprivation, which is stimulatory, acting through a cyclic AMP-dependent mechanism (91, 92). Moreover, an inverse correlation of IGFBP-1 with IGF-I and the GH-dependent proteins ALS and IGFBP-3 during critical illness is consistent with its inverse regulation by $\mathrm{GH}$, as previously suggested (93-95).

The higher IGFBP-1 levels observed in patients who did not survive prolonged critical illness coincided with lower insulin concentrations compared with survivors, for the same range of blood glucose level - a surprising finding considering that these patients are thought to be insulin-resistant (Fig. 7). Whether or not this indicates that insulin secretion also becomes impaired in the long-stay, intensive care patients remains unclear. It is clear, however, that in unfavourable metabolic conditions the hepatocyte alters its production of IGFregulatory proteins, for which the trigger might be reduced hepatocyte substrate availability (theoretically caused by either hepatic hypoperfusion or hypoxia, hypoglycemia, relative insulin deficiency or hepatic insulin resistance) leading to increased cyclic AMP production, which would both suppress IGF-I and ALS (96) and stimulate IGFBP-1 (92). It is unclear to what extent loss of $\mathrm{GH}$ pulsatility may contribute to this switch, but recent data (6) suggest that activation of hepatic IGF-I and ALS expression may require pulsatile $\mathrm{GH}$; similarly, animal studies suggest that suppression of hepatic IGFBP-1 expression by insulin requires acute, rather than prolonged or non-pulsatile, GH action (97).

It remains unclear as to why long-stay, intensive care patients fail to recover and eventually die, in spite of optimal intensive care. Further exploration of the apparent link between serum IGFBP-1 levels and the outcome of prolonged critical illness will shed new light on which pathophysiological processes are crucial for recovery and survival. An understanding of such mechanisms will be of the utmost importance for future progress in intensive care medicine.

\section{Conclusion}

In conclusion, the neuroendocrine stress reponses differ in the acute and the chronic phase of critical illness. In response to an acute and severe stress event, the anterior pituitary actively releases its hormones into the

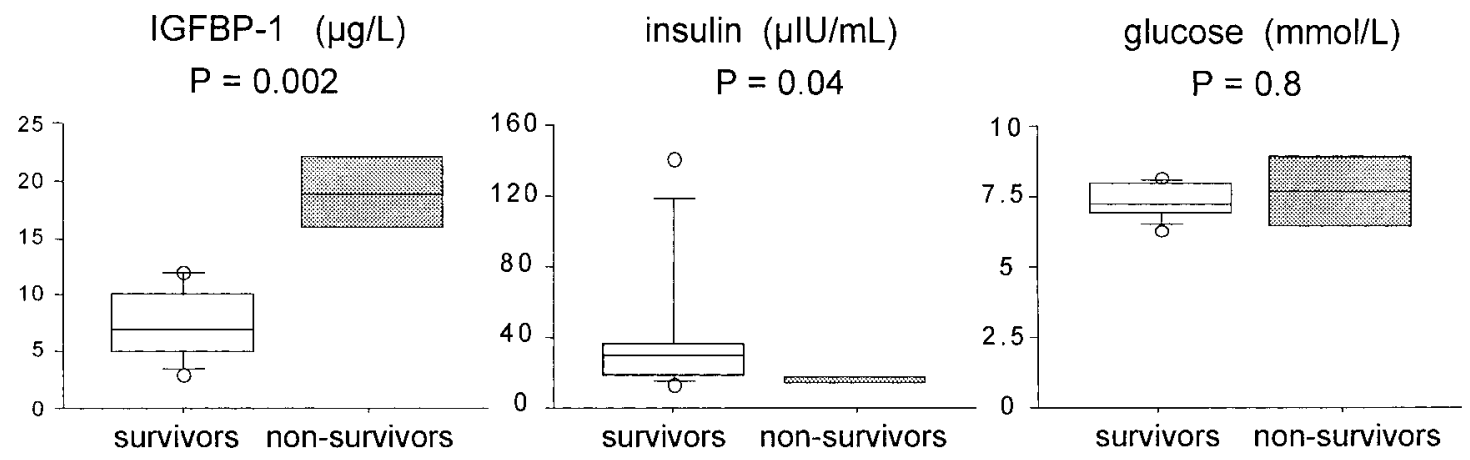

Figure 7 Serum IGFBP-1 concentrations were found to be higher in non-survivors compared with survivors in prolonged critical illness (6). Concomitantly, non-survivors showed lower serum insulin levels for the same blood glucose level. Box plots represent medians, P25-P75 and P10-P90; O, absolute values for outliers. 
circulation while, in the periphery, anabolic target organ hormones are inactivated. This response is thought to be beneficial and adaptive. When critical illness becomes prolonged and the patient continues to need intensive medical care for an extended period, pulsatile secretion of anterior pituitary hormones becomes uniformly reduced, because of reduced (hypothalamic) stimulation, and this underlies the reduced activity of the respective target tissues and the impaired anabolism. This difference in the acute and chronic stress response may not be trivial. Indeed, it was the (inappropriate) assumption that the acute stress responses, such as GH-resistance, persist throughout the course of critical illness which had generated the (inappropriate) justification for the administration of high doses of GH to long-stay, intensive care patients in an attempt to overcome $\mathrm{GH}$ resistance and thus to induce anabolism (98). The specific neuroendocrine disorder present in patients with prolonged critical illness may have predisposed them to the (lethal) sideeffects of that strategy. Since infusing the presumably deficient hypothalamic releasing factors allows restoration of the (global) anterior pituitary function with preserved pulsatility and active feedback-inhibition loops, this targeted, tropic approach, which has proved effective in bringing about anabolism, also appears to be safer in the critically ill as it precludes overtreatment. It remains to be determined whether endocrine intervention with releasing factors in prolonged critical illness will meet the high expectations by accelerating healing and recovery in those patients who have entered the vicious circle of prolonged intensive care dependency.

\section{Acknowledgements}

This work was supported by reseach grants from the Belgian Fund for Scientific Research (G.0162.96, G.0144.00 and G.3C05.95N) and the Research Council for the University of Leuven (OT 95/24 and OT 99/33). This material was presented at the ENEA Young Investigator Award Lecture during the 9th Meeting of the European Neuroendocrine Association (Odense, Denmark, September 4-7, 1999).

\section{References}

1 Streat SJ, Beddoe AH \& Hill GL. Aggressive nutritional support does not prevent protein loss despite fat gain in septic intensive care patients. Journal of Trauma 198727 262-266.

2 Carroll P. Protein metabolism and the use of growth hormone and insulin-like growth factor-I in the critically ill patient. Growth Hormone and IGF Research 19999 400-413.

3 Van den Berghe G, Baxter RC, Weekers F, Wouters P, Bowers CY \& Veldhuis JD. A paradoxical gender dissociation within the growth hormone/insulin-like growth factor I axis during protracted critical illness. Journal of Clinical Endocrinology and Metabolism 200085 183-192.
4 Knaus WA, Draper EA, Wagner DP \& Zimmerman JE. APACHE II: a severity of disease classification system. Critical Care Medicine $198513818-829$.

5 Van den Berghe G, de Zegher F \& Bouillon R. Acute and prolonged critical illness as different neuroendocrine paradigms. Journal of Clinical Endocrinology and Metabolism 199883 1827-1834.

6 Van den Berghe G, Wouters P, Weekers F, Mohan S, Baxter RC, Veldhuis JD et al. Reactivation of pituitary hormone release and metabolic improvement by infusion of growth hormone releasing peptide and thyrotropin-releasing hormone in patients with protracted critical illness. Journal of Clinical Endocrinology and Metabolism 199984 1311-1323.

7 Thorner MO, Vance ML, Laws ER, Horvath E \& Kovacs K. The anterior pituitary. In Williams Textbook of Endocrinology, edn 9, ch 9, pp 249-340. Eds JD Wilson, DW Foster, HM Kronenberg \& PR Larsen. Philadelphia: WB Saunders, 1998.

8 Bowers CY, Momany FA, Reynolds GA \& Hong A. On the in vitro and in vivo activity of a new synthetic hexapeptide that acts on the pituitary to specifically release growth hormone. Endocrinology $19841141537-1545$.

9 Howard AD, Feighner SD, Cully DF, Arena JP, Liberator PA, Rosenblum CI et al. A receptor in pituitary and hypothalamus that functions in growth hormone release. Science 1996273 974-977.

10 Kojima M. Hosoda H. Date Y \& Nakazato M. Ghrelin is a growthhormone-releasing acylated peptide from stomach. Nature 1999 402 656-660.

11 Gevers EF, Wit JM \& Robinson IC. Growth, growth hormone (GH) binding protein, and $\mathrm{GH}$ receptors are differentially regulated by peak and trough components of GH secretory pattern in the rat. Endocrinology 1996137 1013-1018.

12 Giustina A \& Veldhuis JD. Pathophysiology of the neuroregulation of growth hormone secretion in experimental animals and the human. Endocrine Reviews 199819 717-797.

13 Hindmarsh PC, Dennison E, Pincus SM, Cooper C, Fall CHD, Matthews DR et al. A sexually dimorphic pattern of growth hormone secretion in the elderly. Journal of Clinical Endocrinology and Metabolism 199984 2679-2685.

14 Ross R, Miell J, Freeman E, Jones J, Matthews D, Preece M \& Buchanan C. Critically ill patients have high basal growth hormone levels with attenuated oscillatory activity associated with low levels of insulin-like growth factor-1. Clinical Endocrinology $19913547-54$.

15 Voerman HJ, Strack van Schijndel RJM, de Boer H, van der Veen EA \& Thijs LG. Growth hormone: secretion and administration in catabolic adult patients, with emphasis on the critically ill patient. Netherlands Journal of Medicine 199241 229-244.

16 Hartman ML, Veldhuis JD, Johnson ML, Lee MM, Alberti KG, Samojlik E et al. Augmented growth hormone secretory burst frequency and amplitude mediate enhanced GH secretion during a two day fast in normal men. Journal of Clinical Endocrinology and Metabolism 199274 757-765.

17 Hermansson M, Wickelgren RB, Hammerqvist F, Bjarnason R, Wennstrom I, Wernerman J et al. Measurement of human growth hormone receptor messenger ribonucleic acid by a quantitative polymerase chain reaction-based assay: demonstration of reduced expression after elective surgery. Journal of Clinical Endocrinology and Metabolism 199782 421-428.

18 Baxter RC, Hawker FH, To C, Stewart PM \& Holman SR. Thirty day monitoring of insulin-like growth factors and their binding proteins in intensive care unit patients. Growth Hormone and IGF Research 19988 455-463.

19 Rodriguez-Arnao J, Yarwood Y, Ferguson C, Miell J, Hinds CJ \& Ross RJ. Reduction in circulating IGF-I and hepatic IGF-I mRNA levels after caecal ligation and puncture are associated with differential regulation of hepatic IGF-binding protein-1, -2 and -3 mRNA levels. Journal of Endocrinology $1996151287-$ 292.

20 Bentham J, Rodriguez-Arnao-J \& Ross RJ. Acquired growth hormone resistance in patients with hypercatabolism. Hormone Research $19934087-91$. 
21 Timmins AC, Cotterill AM, Cwyfan Hughes SC, Holly JM, Ross RJ, Blum $\mathrm{W}$ et al. Critical illness is associated with low circulating concentrations of insulin-like growth factors-I and -II, alterations in insulin-like growth factor binding proteins, and induction of an insulin-like growth factor binding protein-3 protease. Critical Care Medicine 199624 1460-1466.

22 Gibson FA \& Hinds CJ. Growth hormone and insulin-like growth factors in critical illness. Intensive Care Medicine 199723 369378.

23 Van den Berghe G, de Zegher F, Veldhuis JD, Wouters P, Awouters $\mathrm{M}$, Verbruggen $\mathrm{W}$ et al. The somatotropic axis in critical illness: effect of continuous GHRH and GHRP-2 infusion. Journal of Clinical Endocrinology and Metabolism 199782 590-599.

24 Van den Berghe G, de Zegher F, Baxter RC, Veldhuis JD, Wouters $\mathrm{P}$, Schetz $\mathrm{M}$ et al. Neuroendocrinology of prolonged critical illness: effect of continuous thyrotropin-releasing hormone infusion and its combination with growth hormone-secretagogues. Journal of Clinical Endocrinology and Metabolism 199883 309-319.

25 Van den Berghe G, de Zegher F, Lauwers P \& Veldhuis JD. Growth hormone secretion in critical illness: effect of dopamine. Journal of Clinical Endocrinology and Metabolism 199479 1141-1146.

26 Van den Berghe $\mathrm{G} \&$ de Zegher F. Anterior pituitary function during critical illness and dopamine treatment Critical Care Medicine 199624 1580-1590.

27 Micic D, Popovic V, Doknic M, Macut D, Dieguez C \& Casanueva FF. Preserved growth hormone $(\mathrm{GH})$ secretion in aged and very old subjects after testing with the combined stimulus GHreleasing hormone plus GH-releasing hexapeptide-6. Journal of Clinical Endocrinology and Metabolism 199883 2569-2572.

28 Van den Berghe G, de Zegher F, Bowers CY, Wouters P, Muller P, Soetens $\mathrm{F}$ et al. Pituitary responsiveness to growth hormone $(\mathrm{GH})$ releasing hormone, GH-releasing peptide-2 and thyrotropin releasing hormone in critical illness. Clinical Endocrinology 1996 45 341-351.

29 Michalaki M, Vagenakis A, Kalfarentoz F, Makri M \& Kyriazopoulou V. Is there any role of IL-6, TNF $\alpha$ and cortisol in the pathogenesis of euthyroid sick syndrome? Proceedings of the 81 st Annual Meeting of the Endocrine Society 12-15 June 1999, San Diego, CA, USA. Abstract P3-422.

30 Chopra IJ, Huang TS, Beredo A, Solomon DH, Chua Teco GN \& Mead JF. Evidence for an inhibitor of extrathyroidal conversion of thyroxine to 3,5,3'-triiodothyronine in sera of patients with nonthyroidal illness. Journal of Clinical Endocrinology and Metabolism $198560666-672$.

31 Romijn JA \& Wiersinga WM. Decreased nocturnal surge of thyrotropin in nonthyroidal illness. Journal of Clinical Endocrinology and Metabolism 199070 35-42.

32 Bartalena L, Martino E, Brandi LS, Falcone M, Pacchiarotti A, Ricci C et al. Lack of nocturnal serum thyrotropin surge after surgery. Journal of Clinical Endocrinology and Metabolism 199070 293-296.

33 Schlienger JL, Sapin R, Capgras T, Gasser F, Monassier JP, Hauer B et al. Evaluation of thyroid function after myocardial infarction. Annales d'Endocrinologie 199152 283-288.

34 Rothwell PM \& Lawler PG. Prediction of outcome in intensive care patients using endocrine parameters. Critical Care Medicine 1995 $2378-83$.

35 van der Poll T, van Zee K, Endert E, Coyle S, Stiles D, Prible J et al. Interleukin-1 receptor blockade does not affect endotoxininduced changes in plasma thyroid hormone and thyrotropin concentration in man. Journal of Clinical Endocrinology and Metabolism 199580 1341-1346.

36 Lim CF, Doctor R, Visser TJ, Krenning EP, Bernard B, van Toor H et al. Inhibition of thyroxine transport into cultured rat hepatocytes by serum of non-uremic critically ill patients: effects of bilirubin and non-esterified fatty acids. Journal of Clinical Endocrinology and Metabolism 199376 1165-1172.

37 Gardner DF, Kaplan MM, Stanley CA \& Utiger RD. Effect of triiodothyronine replacement on the metabolic and pituitary responses to starvation. New England Journal of Medicine 1979 300 579-584.

38 De Groot LJ. Dangerous dogmas in medicine: the non-thyroidal illness syndrome. Journal of Clinical Endocrinology and Metabolism $199984151-164$.

39 Kemperer JD, Klein I, Gomez M, Helm RE, Ojamaa K, Thomas SJ et al. Thyroid hormone treatment after coronary bypass surgery. New England Journal of Medicine 1995333 1522-1527.

40 Mullis-Jansson SL, Argenziano M, Corwin S, Homma S, Weinberg AD, Williams $M$ et al. A randomized double blind study on the effect of triiodothyronine on cardiac function and morbidity after coronary bypass surgery. Journal of Thoracic and Cardiovascular Surgery $19991171128-1134$.

41 Van den Berghe G, de Zegher F, Veldhuis JD, Wouters P, Gouwy S, Stockman Wet al. Thyrotropin and prolactin release in prolonged critical illness: dynamics of sponaneous secretion and effects of growth hormone secretagogues. Clinical Endocrinology 199747 599-612.

42 Fliers E, Guldenaar SEF, Wiersinga WM \& Swaab DF. Thyrotropinreleasing hormone gene expression in the human hypothalamus in relation to non-thyroidal illness. Proceedings of the 79th Annual Meeting of the Endocrine Society, 11-14 June 1997, Minneapolis, MN, USA. Abstract OR44-3.

43 Bacci V. Schussler GC \& Kaplan TC. The relationship between serum triiodothyronine and thyrotropin during systemic illness. Journal of Clinical Endocrinology and Metabolism 198254 12291235.

44 Damas P, Reuter A, Gysen P, Demonty J, Lamy M \& Franchimont P. Tumor necrosis factor and interleukin-1 serum levels during severe sepsis in humans. Critical Care Medicine 198917 975978.

45 Faglia G, Ferrari C, Beck-Peccoz P, Spada A, Travaglini P \& Ambrosi B. Reduced plasma thyrotropin response to thyrotropin releasing hormone after dexamethasone administration in normal humans. Hormone and Metabolic Research 19735 289291.

46 Van den Berghe G, de Zegher F \& Lauwers P. Dopamine and the sick euthyroid syndrome in critical illness. Clinical Endocrinology $199441731-737$.

47 Van den Berghe G, Wouters P, Bowers CY, de Zegher F, Bouillon R \& Veldhuis JD. Growth hormone releasing peptide-2 infusion synchronizes growth hormone, thyrotropin and prolactin secretion in prolonged critical illness. European Journal of Endocrinology $199914017-22$.

48 Arem R, Wiener GJ, Kaplan SG, Kim HS, Reichlin S \& Kaplan MM. Reduced tissue thyroid hormone levels in fatal illness. Metabolism $1993421102-1108$.

49 Vaughan GM, Mason AD, McManus WF \& Pruitt BA Jr. Alterations of mental status and thyroid hormones after thermal injury. Journal of Clinical Endocrinology and Metabolism 198560 1221-1225.

50 Brent GA \& Hershman JM. Thyroxine therapy in patients with severe non-thyroidal illnesses and low serum thyroxine concentrations. Journal of Clinical Endocrinology and Metabolism 198663 $1-7$.

51 Becker RA, Vaughan GM, Ziegler MG, Seraille LG, Goldfarb IW, Mansour EH et al. Hypermetabolic low triiodothyronine syndrome in burn injury. Critical Care Medicine 198210 870-875.

52 Bettendorf M, Schmidt KG, Grenz S, Grulich-Henn J \& Heinrich U. Triiodothyronine treatment in children after cardiac surgery: a randomized, placebo-controlled, double-blind clinical study. Proceedings of the 81st Annual Meeting of the Endocrine Society 12-15 June 1999 San Diego, CA, USA. Abstract O12-5.

53 Wang C, Chan V \& Yeung RTT. Effect of surgical stress on pituitary-testicular function. Clinical Endocrinology $19789255-$ 266.

54 Wang C, Chan V, Tse TF \& Yeung RT. Effect of acute myocardial infarction on pituitary testicular function. Clinical Endocrinology $19789249-253$ 
55 Dong Q, Hawker F, McWilliam D, Bangah M, Burger H \& Handelsman DJ. Circulating immunoreactive inhibin and testosterone levels in patients with critical illness. Clinical Endocrinology 199236 399-404.

56 Van den Berghe G, de Zegher F, Lauwers P \& Veldhuis JD. Luteinizing hormone secretion and hypoandrogenemia in critically ill men: effect of dopamine. Clinical Endocrinology 199441 563-569.

57 Russell DH. New aspects of prolactin and immunity: a lymphocyte-derived prolactin-like product and nuclear protein kinase C activation. Trends in Pharmacological Sciences 198910 40-44.

58 Bernton EW, Meltzer MS \& Holaday JW. Suppression of macrophage activation and T-lymphocyte function in hypoprolactinemic mice. Science $1988239401-404$.

59 Russell DH, Larson DF, Cardon SB \& Copeland JG. Cyclosporin inhibits prolactin induction of ornithine decarboxylase in rat tissue. Molecular and Cellular Endocrinology 198435 159-166.

60 Russell DH, Kibler R, Matrisian L, Larson DF, Poulos B \& Magun BE. Prolactin receptors on human T- and B-lymphocytes: antagonism of prolactin-binding by cyclosporin. Journal of Immunology 1985134 3027-3031.

61 Carrier M, Wild J, Pelletier C \& Copeland JG. Bromocriptine as an adjuvant to cyclosporin immunosuppression after heart transplantation. Annals of Thoracic Surgery 199049 129-132.

62 Noel GL, Suh HK, Stone SJG \& Frantz AE. Human prolactin and growth hormone release during surgery and other conditions of stress. Journal of Clinical Endocrinology and Metabolism 197235 $840-851$.

63 Van den Berghe G, de Zegher F \& Lauwers P. Dopamine and the euthyroid sick syndrome in critical illness. Clinical Endocrinology $199441731-737$.

64 Meakins JL, Pietsch JB, Bubenick O, Kelly R, Rode H, Gordon J et al. Delayed hypersensitivity: indicator of acquired failure of host defenses in sepsis and trauma. Annals of Surgery $1977188241-$ 250.

65 Devins SS, Miller A, Herndon BL, O'Toole L \& Reisz G. Effects of dopamine on T-lymphocyte proliferative responses and serum prolactin concentrations in critically ill patients. Critical Care Medicine $19922639682-9685$.

66 Belchetz PE, Plant TM, Nakai Y, Keogh EJ \& Knobil E. Hypophyseal responses to continuous and intermittent delivery of hypothalamic gonadotropin-releasing hormone. Science 1978202631 633.

67 Santoro N, Filicori M \& Crowley Jr WF. Hypogonadotropic disorders in men and women: diagnosis and therapy with pulsatile gonadotropin releasing hormone. Endocrine Reviews $1986711-23$

68 Klibanski A, Beitens IZ, Badger TM, Little R \& McArthur J. Reproductive function during fasting in man. Journal of Clinical Endocrinology and Metabolism 198153 258-266.

69 Veldhuis JD, Iranmanesh A, Evans WS, Lizarralde G, Thorner MO \& Vance ML. Amplitude suppression of the pulsatile mode of immunoradiometric LH release in fasting-induced hypoandrogenemia in normal men. Journal of Clinical Endocrinology and Metabolism 199376 587-593.

70 Vogel AV, Peake GT \& Rada RT. Pituitary-testicular axis dysfunction in burned men. Journal of Clinical Endocrinology and Metabolism $198560658-665$.

71 Lephart ED, Baxter CR \& Parker CR Jr. Effect of burn trauma on adrenal and testicular steroid hormone production. Journal of Clinical Endocrinology and Metabolism 198764 842-848.

72 Kreutz LD, Rose RM \& Jennings JR. Suppression of plasma testosterone levels and psychological stress: a longitudinal study of young men in officer candidate school. Archives of General Psychiatry 197226 479-482.

73 Aakvaag A, Bentdal O, Quigstad K, Walstad P, Ronningen H \& Fonnum F. Testosterone and testosterone binding globulin in young men during prolonged stress. International Journal of Andrology $1978122-31$.
74 Rivier C \& Vale W. In the rat, interleukin 1- $\alpha$ acts at the level of the brain and the gonads to interfere with gonadotropin and sex steroid secretion. Endocrinology 1989124 2105-2109.

75 Guo H, Calkins JH, Sigel MM \& Lin T. Interleukin-2 is a potent inhibitor of Leydig cell steroidogenesis. Endocrinology 1990127 1234-1239.

76 Woolf PD, Hamill RW, McDonald JV, Lee LA \& Kelly M. Transient hypogonadotropic hypogonadism caused by critical illness. Journal of Clinical Endocrinology and Metabolism $198560444-$ 450 .

77 Spratt DI, Cox P, Orav J, Moloney J \& Bigos T. Reproductive axis suppression in acute illness is related to disease severity. Journal of Clinical Endocrinology and Metabolism 199376 1548-1554.

78 Cicero TJ, Bell RD, Wiest WG, Allison JH, Polakoski K \& Robins E. Function of the male sex organs in heroin and methadone users. New England Journal of Medicine 1975292 882-887.

79 Tweedle D, Walton C \& Johnston IDA. The effect of an anabolic steroid on postoperative nitrogen balance. British Journal of Clinical Practice 197227 130-132.

80 O'Leary E, Hubbard K, Tormey W \& Cunningham AJ. Laparoscopic cholecystectomy: haemodynamic and neuroendocrine responses after pneumoperitoneum and changes in position. British Journal of Anaesthesia 199676 640-644.

81 Munck A. Guyre P \& Holbrook N. Physiological functions of glucocorticoids during stress and their relation to pharmacological actions. Endocrine Reviews 19845 25-44.

82 Starling EH. The Wisdom of The Body. The Harveian Oration delivered to the Royal College of Physicians, London. London: HK Lewis, 1923.

83 Cannon WB. The Wisdom of The Body. New York: Norton, 1932.

84 Vermes I, Bieshuizen A, Hampsink RM \& Haanen C. Dissociation of plasma adrenocorticotropin and cortisol levels in critically ill patients: possible role of endothelin and atrial natriuretic hormone. Journal of Clinical Endocrinology and Metabolism 1995 80 1238-1242.

85 Suzuki T, Suzuki N, Daynes RA \& Engleman EG. Dehydroepiandrosterone enhances IL2 production and cytotoxic effector function of human T-cells. Clinical Immunology and Immunopathology $199161202-211$.

86 Parker LN, Levin ER \& Lifrak ET. Evidence for adrenocortical adaptation to severe illness. Journal of Clinical Endocrinology and Metabolism $198560947-952$.

87 Van den Berghe G, de Zegher F, Schetz M, Verwaest C, Ferdinande P \& Lauwers P. Dehydroepiandrosterone sulphate in critical illness: effect of dopamine. Clinical Endocrinology $199543457-$ 463.

88 Zipser RD, Davenport MW, Martin KL, Tuck ML, Warner NE, Swinney RR et al. Hyperreninemic hypoaldosteronism in the critically ill: a new entity. Journal of Clinical Endocrinology and Metabolism 198153 867-873.

89 Barquist E \& Kirton O. Adrenal insufficiency in the surgical intensive care unit patient. Journal of Trauma 199742 27-31.

90 Yeoh SI \& Baxter RC. Metabolic regulation of the growth hormone independent insulin-like growth factor binding protein in human plasma. Acta Endocrinologica 1988119 465-473.

91 Lewitt MS \& Baxter RC. Regulation of growth hormoneindependent insulin-like growth factor-binding protein (BP-28) in cultured human fetal liver explants. Journal of Clinical Endocrinology and Metabolism 198969 246-252.

92 Lewitt MS \& Baxter RC. Inhibitors of glucose uptake stimulate the production of insulin-like growth factor binding protein (IGFBP1) by human fetal liver. Endocrinology 1990126 1527-1533.

93 Baxter RC. Circulating binding proteins for the insulin-like growth factors. Trends in Endocrinology and Metabolism 19934 91-96.

94 Norrelund H, Fisker S, Vahl N, Borglum J, Richelsen B, Christiansen JS et al. Evidence supporting a direct suppressive effect of growth hormone on serum IGFBP-1 levels: experimental studies in normal, obese and GH-deficient adults. Growth Hormone and IGF Research 19999 52-60. 
95 Olivecrona H, Hilding A, Ekström C, Barle H, Nyberg B, Möller C et al. Acute and short-term effects of growth hormone on insulin-like growth factors and their binding proteins: serum levels and hepatic messenger ribonucleic acid responses in humans. Journal of Clinical Endocrinology and Metabolism 1999 $84553-560$.

96 Delhanty PJD \& Baxter RC. The regulation of acid-labile subunit gene expression and secretion by cyclic adenosine $3^{\prime}, 5^{\prime}$-monophosphate. Endocrinology $1998139260-265$.

$97 \mathrm{Hu} \mathrm{M}$, Robertson DG \& Murphy LJ. Growth hormone modulates insulin regulation of hepatic insulin-like growth factor binding protein-1 transcription. Endocrinology 1996137 3702-3709.

98 Takala J, Ruokonen E, Webster NR, Nielsen MS, Zandstra DF, Vundelinckx G et al. Increased mortality associated with growth hormone treatment in critically ill adults. New England Journal of Medicine $1999341785-792$.

Received 25 January 2000

Accepted 7 March 2000 